\title{
Prevention as an Explicit Part of the Social Work Profession: Part Two of a Systematic Investigation
}

\author{
Emily L. McCave \\ Carrie Rishel \\ Meagann Morris
}

\begin{abstract}
In 2011, Advances in Social Work published results from an investigation into the explicit use of "prevention" language within the social work profession. Findings from this study highlighted a gap in the knowledge and integration of prevention-focused social work education and practice. A recommendation was made to examine additional indicators that illustrate the extent to which "prevention" is an accepted and growing subfield within the social work academy. This second paper continues the inquiry by examining three additional indicators for integration of prevention content, including: 1) CSWE accredited MSW programs; 2) social work textbooks; and 3) abstracts accepted at two national social work conferences. Although findings demonstrate that about a quarter of MSW programs integrate prevention content into their curriculum there is a lack of prevention content available within social work textbooks and professional conferences for social work scholars and practitioners. Barriers and supports to addressing these issues are discussed.
\end{abstract}

Keywords: Prevention, social work education, social work profession

The United States is facing a period of rapid change in health care delivery and services. Most service delivery models have traditionally been designed to address the treatment of disease, with comparably little resources allocated toward the prevention of health problems (Miles, Espiritu, Horen, Sebiam, \& Waetzig, 2010; Schroeder, 2007). Despite spending more money on health care than any other country (Borger et al., 2006), the United States ranks low on most measures of health outcomes (Schroeder, 2007). Longstanding health disparities among vulnerable and disadvantaged populations persist, with little indication of improvement (Miles et al., 2010). Large-scale population shifts, including increasing aging and veteran populations that may require multiple types of services, will likely make a critical impact on future health service delivery (Oliver \& DeCoster, 2006; Wheeler \& Bragin, 2007). The current national attention on health care reform foreshadows upcoming changes in delivery practices. The Affordable Care Act (ACA) will dramatically influence the delivery of health services through the creation of accountable care organizations, health homes, and preventive integrated care (Wotring \& Stroul, 2011). social workers, as key providers of health education and services, must capitalize on the opportunity for change in the era of health care reform.

The need for a prevention-focused approach is clear. Nearly half of all deaths are associated with preventable health conditions. Over $90 \%$ of US health care dollars,

Emily L. McCave, MSW, Ph.D., is an Assistant Professor in the Department of Social Work at Quinnipiac University in Hamden, CT; Carrie Rishel, MSW, Ph.D., is an Associate Professor in the School of Social Work at West Virginia University in Morgantown, WV; Meagann Morris, MSW, is a graduate of the School of Social Work at West Virginia University and is a social worker at Family Advantage, LLC. 
however, are spent on treatment, with about $2 \%$ allocated for universal (or populationbased) prevention (Mokdad, Marks, Stroup, \& Gerberding, 2004). A rapidly expanding empirical research base supports the efficacy and effectiveness of prevention efforts (Rishel, 2007). The vast majority of this research has been conducted by scholars in psychology, many of whom have long been advocating for expanding the multidisciplinary focus on prevention (Weisz, Sandler, Durlak, \& Anton, 2005). Several other professions, including psychiatry, nursing, and counseling psychology, are currently addressing their professional role in prevention (Marshall et al., 2011). Social workers, however, appear to be largely absent from either national or professional dialogue regarding prevention approaches to health care services.

As noted in Part 1 of this two-part investigation (McCave \& Rishel, 2011), prevention efforts have been relegated to the margins, rather than acknowledged as a central aspect of social work throughout most of the profession's history (McCave \& Rishel, 2011; Woody, 2006). This assertion is based on the finding that there are few publications addressing prevention within the professional literature (Mashall et al., 2011; McCave \& Rishel, 2011) and limited attention to prevention within the official policy statements compiled in Social Work Speaks (McCave \& Rishel, 2011). Although the initial indicators examined document sporadic episodes of particular interest in prevention, it appears that the profession as a whole has yet to embrace prevention as a core element of social work practice (McCave \& Rishel, 2011).

\section{Current Project}

As social work scholars interested in strengthening prevention content in our social work courses, we began to examine the current state of prevention in social work. Our initial project, published last year in Advances in Social Work (McCave \& Rishel, 2011), focused on examining the explicit prevention content in the social work literature, the current Council on Social Work Education (CSWE) standards for social work educational programs (EPAS), and the National Association of Social Work's (NASW's) most recent publication of Social Work Speaks. At the conclusion of that investigation, we recommended that additional indicators be examined for explicit prevention content. Consequently, the current project focuses on three more "indicators" of the status of prevention in the social work profession. These indicators include: 1) accredited MSW programs in the United States, 2) social work texts, and 3) social work annual conference proceedings. Similar to our first project, this current research focuses solely on "explicit" rather than "implicit" evidence of prevention content within the social work profession.

\section{Methodology}

As mentioned above, three "indicators" of explicit prevention content were examined for this current project. The first indicator was the explicit prevention content within accredited MSW programs. This was done through an in-depth online review of all accredited MSW programs in the United States, which included numerous steps. The initial step was to identify all accredited MSW programs in the U.S. through the CSWE directory of MSW programs in each state. From there we engaged in an online search that 
would allow us to document the extent to which prevention was explicitly mentioned in each program.

A tiered online search occurred, such that initially, all the programs with a specified joint or dual degree with a Master in Public Health (MPH) program at that University were identified from the entire sampling frame. The joint or dual degree with an MPH program was determined to be an indicator of an explicit focus on prevention content; according to the American Public Health Association (n.d.), the discipline of Public Health is focused on prevention of disease and the promotion of health in all individuals, from local to global communities. From there, a review of all the remaining MSW programs was completed, with a focus on those programs that offered a concentration with the term "prevention" mentioned in the title or description. The remaining MSW programs with neither a joint/dual degree MSW/MPH program or a prevention-focused concentration were examined in terms of their course offerings. Those programs that offered one or more courses with prevention in the title or description were identified. Once all three levels of this search were completed, additional information was gathered about the Universities identified to highlight broader similarities. This information included: 1) the geographic region of the University; 2) the University's status as public or private; 3 ) the presence of a social work $\mathrm{PhD}$ program; and 4) the designation of the MSW program as being housed in a School of social work or a Division/Department.

The second indicator was an in-depth review of the explicit prevention content in social work textbooks over the past several decades. This occurred through conducting several online searches of textbook holdings, namely our University's library catalog, well-known social work text publishers, along with a targeted search in Google Scholar and Google Books. The search parameters included any textbook that had "prevention" and "social work" in the title with no limit on the date published. All of the books that were identified were obtained through the University's library. These books were then examined to determine whether they were a text or monograph that was a substantive book on social work and prevention, in terms of theoretical contribution, or if the book was focused on a more narrow aspect of prevention and social work (e.g., juvenile justice).

The final indicator used in this analysis was the presence of explicit prevention content in the abstracts selected for presentation at the recent annual conferences of both CSWE (2012) and the Society for Social Work Research (SSWR; 2013). This was done through searching the online conference schedules for the number of abstracts that used the word "prevention" in the title and determining the topics covered by these abstracts.

\section{Results}

\section{Accredited MSW Programs}

When researching the accredited Master of social work programs we looked at the online descriptions of the courses and concentrations offered by each school as well as identified programs that have an established joint or dual degree with a MPH program. Table 1 provides a breakdown of the characteristics of the MSW programs that were 
identified. Just under 15\% (32) of accredited MSW programs also had a joint or dual degree with a MPH program. A majority of these programs were found within a School of social work at a public University that also offered a $\mathrm{PhD}$ in social work. Of the 216 programs that did not have an MSW/MPH program, 57 programs (26.64\%) offered MSW courses that had some focus on prevention, as indicated by having the term "prevention" in either the title or description of the course. A much smaller proportion of the programs (2.78\%) had a concentration that focused explicitly on prevention, as indicated by having the word "prevention" in the description; there were no programs with the term "prevention" in the title of a concentration.

Table 1. Breakdown of Accredited MSW Programs with an Identified Prevention Focus

\begin{tabular}{|c|c|}
\hline Category & Total \# \\
\hline Schools with a Dual MSW/MPH Program & 32 \\
\hline \multicolumn{2}{|l|}{ Schools with MSW/MPH by Region (Regions established by Census) } \\
\hline \multicolumn{2}{|l|}{ NORTHEAST } \\
\hline New England (CT, ME, MA, NH, RI, VT) & 2 \\
\hline Mid Atlantic (NJ, NY, PA) & 6 \\
\hline \multicolumn{2}{|l|}{ MIDWEST } \\
\hline East North Central (IN, IL, MI, OH, WI) & 3 \\
\hline West North Central (IA, KS, MN, MO, NE, ND, SD) & 4 \\
\hline \multicolumn{2}{|l|}{ SOUTH } \\
\hline South Atlantic (DE, DC, FL, GA, MD, NC, SC, VA, WV) & 5 \\
\hline East South Central (AL, KY, MS, TN) & 1 \\
\hline West South Central (AR, LA, OK, TX) & 4 \\
\hline \multicolumn{2}{|l|}{ WEST } \\
\hline Mountain (AZ, CO, ID, NM, MT, UT, NV, WY) & 2 \\
\hline Pacific (AK, CA, HI, OR, WA) & 5 \\
\hline \multicolumn{2}{|l|}{ Schools with MSW/MPH: Private vs. Public } \\
\hline Private & 7 \\
\hline Public & 25 \\
\hline \multicolumn{2}{|l|}{ Schools with MSW/MPH: Schools of Social Work vs. Divisions/Departments } \\
\hline Schools of Social Work & 28 \\
\hline Divisions/Departments & 4 \\
\hline Schools with MSW/MPH: Have a PhD in Social Work Program & 25 \\
\hline Schools with a Concentration with a Focus on Prevention (but no MSW/MPH) & 6 \\
\hline $\begin{array}{l}\text { Schools with Course that Focus on Prevention (but no MSW/MPH or } \\
\text { Concentration) }\end{array}$ & 57 \\
\hline Total Number of Accredited MSW Programs in the United States & 216 \\
\hline
\end{tabular}




\section{Prevention and SW Texts}

After following the search steps described above to examine textbooks, we were unable to identify any currently available textbooks that substantively address social work and prevention. Specifically, upon examination of the search results, there was not a single contemporary book found that included both "social work" and "prevention" in the title. Further, after reviewing nine books (including textbooks, monographs, and curriculum compendiums) that were secured through the library, it was determined that there is not a substantive text using a prevention framework for social work practice. Multiple books and monographs were found that were published in the early 1980s such as: Prevention in Mental Health and Social Work: A Sourcebook of Curriculum and Teaching Materials (Nobel, 1981); Primary Prevention Approaches to the Development of Mental Health Services for Ethnic Minorities: A Challenge to Social Work Education and Practice (Miller, Styles O’Neal, \& Scott, 1982); and Education for Primary Prevention in Social Work (Bowker, 1983). None of these, however, could be considered a textbook utilizing a prevention framework for social work practice. In several of these books and monographs, we found reference to a National Institute of Mental Health (NIMH) grant awarded to CSWE in 1978 to promote the development of curriculum and teaching materials on primary prevention in mental health and social work. Products from this project included a source book including curriculum and teaching materials on primary prevention and a manual of course outlines on prevention. After the series of publications that appeared in the 1980s, no other books were identified that contained both "social work" and "prevention" in the title.

\section{Prevention and CSWE/SSWR Meetings}

Currently there is not a track at either CSWE's or SSWR's annual conference focused specifically on prevention in social work practice and/or education, nor is there a special interest group focused on prevention at either conference. A review of abstracts selected for presentation at the CSWE Annual Program Meeting (2012) and the SSWR annual meeting (2013) revealed that a very small number of accepted abstracts contained the word "prevention" in the title. There were over 600 educational sessions offered at the 2012 CSWE conference and over 500 educational sessions offered at the SSWR conference. Table 2 provides information on the number of accepted abstracts for CSWE (13) and SSWR (20) with the word "prevention" in the title and the topic areas of these abstracts. Almost all accepted abstracts with "prevention" in the title fit into a specific topic area within social work (e.g. violence prevention), with only one (McCave \& Rishel, 2012)) that focused on the broader role of prevention in social work education and practice. Additionally, when a keyword search for "prevention" anywhere in the abstracts was conducted, an additional 26 CSWE abstracts and 122 SSWR abstracts were identified; however, when looking further at the topic areas of these abstracts the authors found many of these abstracts did not readily fit into the topic areas presented in Table 2 and some did not actually appear to have a prevention focus. 
Table 2. CSWE and SSWR Abstracts

\begin{tabular}{lcc}
\hline Topic & CSWE 2012 & SSWR 2013 \\
\hline "Prevention “ or variation in abstract title & 13 & 20 \\
Violence Prevention & 5 & 6 \\
HIV prevention-related & 4 & 6 \\
Sexual health/family planning prevention & 1 & 3 \\
School-based delinquency prevention & 1 & 0 \\
Public sector prevention & 1 & 0 \\
Prevention in SW education & 1 & 0 \\
Child abuse prevention & 0 & 2 \\
Evidence-based prevention for youth & 0 & 2 \\
School-based prevention of academic problems & 0 & 1 \\
\hline
\end{tabular}

\section{Discussion}

Over the past two decades there has been a lack of conceptual articles discussing how to integrate prevention-focused content into social work research, practice, and education. In addition to this, there are limited avenues for those wishing to cultivate and disseminate innovative prevention-focused research, curriculum, and practice; yet this is exactly what is needed to meet the current needs of the clients being served by social workers in our communities. There are several ways in which innovation and dissemination can be stimulated, such as through creating special topic issues in social work journals, creating prevention tracks at national social work conferences, and establishing a formalized social network (e.g., listserv) for social work scholars who are interested in prevention, to name a few.

\section{Social Work Education}

Within social work education, it is necessary for CSWE to examine the current EPAS standards and determine what changes may be considered for the next revised standards to improve the integration of prevention-focused content into social work education. Until then, social work programs across the country can utilize the current affirmation/reaffirmation process to assess the degree to which this integration is occurring and where improvements can be made to the explicit curriculum. Programs also have the option of infusing prevention content into all of their courses or key required courses, creating electives, certificates, or concentration(s) with a prevention focus, or establishing a joint/dual degree with a MPH program.

Further, one way in which social work education will be enhanced is to train both faculty and students in an established model of prevention practice. Yet the limited dialogue regarding the role of prevention in social work has hindered the development of 
an operational definition of prevention practice. The social work profession has recently shifted toward a competency based education model as defined in the 2008 EPAS. Therefore, efforts to integrate prevention content into the curriculum must reflect competency based educational goals. To effectively develop and implement prevention content in the social work curriculum, it is first necessary to define prevention practice. In other words, what is a social work practitioner who is competent in prevention practice able to do? To initiate this dialogue, Rishel (in press) has proposed a working definition of competent prevention practice. Practitioners competent in prevention practice are able to:

- Explain the definition of "prevention" and the different levels (e.g. universal, selective, indicated) of prevention interventions;

- Articulate the benefits, advantages, and challenges of prevention, and advocate for prevention practices and policy;

- Apply a risk and protective factor framework to identify those at higher risk;

- Identify multiple levels for prevention intervention drawing on their base in ecological systems theory;

- Access, implement, and evaluate evidence-based prevention interventions; and

- Facilitate multidisciplinary collaborative prevention efforts.

The bulleted items above could be used as practice behaviors to define a preventionfocused competency within an advanced concentration. As X notes, this definition is a "work in progress." Further dialogue within the profession will build upon and strengthen this definition as social workers recognize prevention as a core component of social work practice.

\section{Application Examples}

An example of the elective development strategy is one of the author's development and implementation of a specialized MSW elective, Child Mental Health: Promotion, Prevention, and Treatment. The course was designed to prepare students to practice in various settings in a way that promotes and optimizes children's mental health. The course is differentiated from typical course offerings in mental health by inclusion and emphasis of prevention content. Prevention content is incorporated throughout all aspects of the course with the expectation that students will feel equally comfortable identifying and implementing prevention and treatment interventions upon course completion. Please see $\mathrm{X}$ for a complete discussion of the content and evaluation of this course.

Another strategy involves integrating prevention as a key component in specialized MSW training programs. Responding to training grant opportunities is one mechanism of developing specialized training programs. For example, the U.S. Department of Health and Human Services, Health Resources and Services Administration (HRSA) awarded 24 Mental and Behavioral Health Education and Training (MBHET) grants to graduate social work and psychology programs in 2012. Funded under the Affordable Care Act, 
additional MBHET grants are anticipated to be awarded in 2013 and beyond. The authors' institution was one of 11 MSW programs awarded a MBHET grant in 2012. This award funds the implementation of the Integrated Mental and Behavioral Health Training Program (IMBTP). The purpose of the IMBTP is to train MSW students in mental and behavioral health practice, with a focus on integrated and culturally appropriate models of rural service delivery. One of the core components of the program is a focus on integrated models of service delivery, with integrated prevention and treatment models heavily emphasized. As the focus of the training is clinical practice, students trained under this program will be prepared to integrate prevention interventions into standard mental and behavioral health practice settings.

\section{Challenges}

While the need for innovation, dissemination, as well as utilization of prevention practice in social work is clear, there are distinct challenges that exist for many social work practitioners, scholars, students, and educators. The primary challenge is connected to limited resources including time, money, expertise/knowledge, and mentorship. Such resources are critical in order to build a strong and competent workforce of preventionfocused practitioners and scholars. For those scholars who do have the expertise, providing mentorship to junior faculty as well as taking a leadership role in revising the curriculum are resource-heavy endeavors. Increasingly, faculty workloads reflect not only the scholarly interests of faculty but also the demands of the program and service needs of the institution. Additionally, in order for changes to be made at the curricular level, consistent support needs to be obtained from faculty as well as administrators; asking faculty to change their syllabi requires time and energy. Further, choosing to offer a new elective potentially takes the place of an existing elective, a potential source of faculty conflict. Establishing a joint/dual degree with a MPH program may not be part of the shared vision for the program and will likely take months of effort from faculty and administration from both programs. An additional challenge to the implementation of prevention practice relates to the heavy workloads practitioners are often negotiating in their agencies and communities, typically with limited access to social work scholarship and mentorship outside their existing practice background and expertise.

\section{Supports}

Despite the challenges that are present, several supports are available to improve the likelihood of the social work profession becoming more prevention-oriented. Universities often offer internal grants or funding to stimulate innovative research or curriculum development as well as provide assistance to junior faculty who may wish to seek external funding from federal funders or foundations. Further, it has been our experience that colleagues in Public Health, Community Medicine, Psychology, and Nursing, have been very interested in cultivating and sustaining informal and formal relationships. Such resources can be capitalized on for those teaching in institutions where these degrees are offered. Additional networking with stakeholders both within and outside the Institution, such as students, deans, practitioners, and state NASW chapters can be incredibly useful for garnering support for curricular changes. Making the connection to social work 
practice and the potential impact for the practice community and the clients they serve is key.

\section{Limitations}

The research for this project represents a snapshot in time. In regards to the online search of accredited MSW programs, it is likely that some programs were not identified that do in fact offer courses or concentrations focused on prevention because of limited access to online information. It is certainly expected that programs are in a constant state of development, such that at any given time there are courses, concentrations, and dual degree relationships being developed or changed, as well as new MSW programs beginning candidacy. Additionally, based on information available online, it was not possible to determine the number or topic areas of the abstracts submitted, but not accepted, to either CSWE or SSWR. As such, a vital piece of information is missing, which is whether the number of accepted abstracts is proportional to the number of abstracts submitted or whether the small number of accepted abstracts is indicative of a lag in broader acceptance of the focus on prevention in social work education and practice. Further, it may be possible that the low number of accepted abstracts with a prevention focus may reflect a growing number of social work scholars who choose not to submit to either CSWE or SSWR due to a perception that prevention is not a valued topic at CSWE or SSWR and coinciding low acceptance rates. Instead these scholars may submit their work to interdisciplinary, topic/population-specific, or prevention-focused conferences, such as the Society for Prevention Research (SPR) and the American Public Health Association (APHA), both of which welcome social work research. This may have an unfortunate cyclical effect with fewer submissions leading to a justification for fewer acceptances and overall lack of prevention focus at CSWE and SSWR.

\section{Next Steps}

There are several steps that can be taken by social work educators and scholars to assist in the promotion of prevention-focused practice and scholarship. One step is to gather data from social work scholars and practitioners via interviews, surveys, and/or focus groups about their existing knowledge and use of prevention theory and practice. As part of this data collection or as a separate endeavor, it is important that the practice community have an opportunity to discuss ways in which they could better integrate innovative scholarship and theory into their practice. social work scholars need to understand the needs of social work practitioners as they relate to prevention practice. As a way to build a community for those social work scholars interested in prevention, the formation of a special interest group at CSWE and SSWR on prevention in social work as well as an organized effort to advocate for a track on abstracts to be submitted within this topic area is recommended. Additionally, social work students and faculty could benefit from expanding their professional network through a new social work Listserv focused on prevention practice, education, and research.

Another step would be to establish a working group or taskforce to provide recommendations regarding the integration of prevention content into existing social work curricula. This could occur within the context of a single institution as part of 
ongoing curriculum improvement efforts. It could also be an initiative within CSWE to create such a group to review current EPAS standards and consider prevention language for the upcoming 2015 standards. In connection to this, it would be worthwhile to explore the benefit of offering prevention-focused content within social work education, ranging from one elective to a joint/dual degree program with Public Health. Determining the types of employment secured after graduation as well as the level of preparedness for the skills necessary in these positions would be beneficial. Given the small proportion of social work MSW programs that offer a focus on prevention, it is important that data be collected to determine whether or not there is an impact or added benefit to creating prevention-focused courses or developing joint MSW/MPH programs. Lastly, a prevention social work text is clearly needed and is an endeavor that we hope to pursue in the future.

\section{Conclusion}

Prevention is a critical aspect of social work practice, yet, over the past two decades, there has been little formal support provided for students, faculty, and practitioners who recognize the importance of prevention in social work. This investigation was the second part of a continued effort to determine the extent of explicit prevention within the social work profession. As we found in the first inquiry, there is certainly a gap in the knowledge base as well as opportunities for dissemination for scholars and practitioners who view prevention as an essential aspect of the profession. A major paradigm shift in the social work profession toward prevention-focused practice can only come from within; this article is not only a vehicle for dissemination of information but also serves as a call to those who recognize the validity of the statement that prevention practice is social work practice. Without such a cultural shift within the profession, it is likely that the status quo (i.e., treatment first, prevention last mentality) will persist. Adding a patchwork of social work educators and practitioners who understand and value prevention theories and interventions leads to a fragmented system of care. A professionwide shift would instead result in a new generation of social workers who possess the requisite knowledge and skill set to target a myriad of social issues, at all levels of practice, that can be effectively addressed through a prevention framework. It is the hope that this investigation initiates a profession-wide dialogue, as well as promotes new course development, scholarship, and interventions.

\section{References}

American Public Health Association. (n.d.). Get the facts: What is Public Health? Retrieved from http://www.apha.org/NR/rdonlyres/C57478B8-8682-4347-8DDFA1E24E82B919/0/what_is_PH_May1_Final.pdf

Borger, C., Smith, S., Truffer, C., Keehan, S., Sisko, A., Poisal, J., \& Clemen, M. K. (2006). Health spending projections through 2015: Changes on the horizon. Health Affairs, 25, 61-73.

Bowker, J. P. (1983). Education for primary prevention in social work. New York, NY: Council on Social Work Education . 
Marshall, J. W., Ruth, B. J., Sisco, S., Bethke, C., Piper, T. M., Cohen, M., \& Bachman, S. (2011). Social work interest in prevention: A content analysis of the professional literature. Social Work, 56, 201-211.

McCave, E. L., \& Rishel, C. W. (2011). Prevention as an explicit part of the social work profession: A systematic investigation. Advances in Social Work, 12, 226-240.

Miles, J., Espiritu, R. C., Horen, N., Sebian, J., \& Waetzig, E. (2010). A public health approach to children's mental health: A conceptual framework. Washington, DC: Georgetown University Center for Child and Human Development, National Technical Assistance Center for Children's Mental Health.

Miller, S. O., Styles O'Neal, G. M., \& Scott, C.A. (1982). Primary prevention approaches to the development of mental health services for ethnic minorities: A challenge to social work education and practice. New York, NY: Council on Social Work Education.

Mokdad, A. H., Marks, J. S., Stroup, D. E., \& Gerberding, J. L. (2004). Actual causes of death in the United States, 2000. JAMA, 291, 1238-1245.

Nobel, M. (1981). Primary prevention in mental health and social work: A sourcebook of curriculum and teaching materials. New York, NY: Council on Social Work Education.

Oliver, D. P., \& DeCoster, V. A. (2006). Health care needs of aging adults: Unprecedented opportunities for social work. Health \& Social Work, 31, 243-245.

Rishel, C. W. (2007). Evidence-based prevention practice in mental health: What is it and how do we get there? American Journal of Orthopsychiatry, 77, 153-164.

Rishel, C. W. (In Press). Integrating prevention content into clinical social work practice courses. Journal of Social Work Education.

Rishel, C. W., \& McCave, E. L. (2012, November). Formalizing prevention as an explicit part of the social work curriculum. Curriculum workshop presented at the Annual Program Meeting of the Council on Social Work Education, Washington, DC.

Schroeder, S. A. (2007). We can do better - Improving the health of the American people. New England Journal of Medicine, 357, 1221-1228.

Weisz, J. R., Sandler, I. N., Durlak, J. A., \& Anton, B. A. (2005). Promoting and protecting youth mental health through evidence-based prevention and treatment. American Psychologist, 60, 628-648.

Wheeler, D. P., \& Bragin, M. (2007). Bringing it all back home: Social work and the challenge of returning veterans [National Health Line]. Health \& Social Work, 32, 297-300.

Woody, J. D. (2006). Prevention: Making a shadow component a real goal in social work. Advances in Social Work, 7, 44-61. 
Wotring, J., \& Stroul, B. (2011). Issue Brief: The intersect of health reform and systems of care for children's behavioral health care. Washington, DC: Georgetown University Center for Child and Human Development, National Center for Children's Mental Health.

\section{Author note:}

Address correspondence to: Carrie Rishel, Ph.D., Associate Professor, School of Social Work, West Virginia University, PO Box 6830, Morgantown, WV 26506. Email:

Carrie.rishel@mail.wvu.edu 